\title{
Natural and Semisynthetic Triterpenes from Combretum leprosum Mart. with Antiplasmodial Activity
}

\author{
Guilherme M. Passarini, ${ }^{\oplus *, a, b, c}$ Amália S. Ferreira, ${ }^{\circledR b}$ Leandro S. Moreira-Dill, ${ }^{\oplus c, d}$ \\ Fernando B. Zanchi, ${ }^{a, d, e}$ Aurileya G. de Jesus, ${ }^{\odot b}{ }^{b}$ Valdir A. Facundo ${ }^{c, e}$ and \\ Carolina B. G. Teles ${ }^{\circledR a, b, f}$ \\ ${ }^{a}$ Programa de Pós-Graduação em Biologia Experimental, \\ Universidade Federal de Rondônia (PGBIOEXP), 76801-059 Porto Velho-RO, Brazil \\ ${ }^{b}$ Plataforma de Bioensaios de Malaria e Leishmaniose, Fundação Oswaldo Cruz, \\ Rondônia (FIOCRUZ RO), 76812-245 Porto Velho-RO, Brazil \\ ${ }^{c}$ Laboratório de Pesquisa em Química de Produtos Naturais, UNIR, \\ 76801-059 Porto Velho-RO, Brazil \\ ${ }^{d}$ Laboratório de Bioinformática e Química Medicinal (FIOCRUZ RO), \\ 76801-059 Porto Velho-RO, Brazil \\ ePrograma de Pós-Graduação, Rede Bionorte/Rondônia, 76804-421 Porto Velho-RO, Brazil

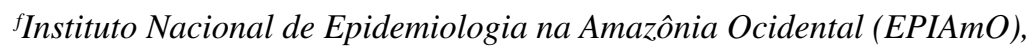 \\ Rua da Beira, 7671, BR 364, km 3.5, Bairro Lagoa 76812-245 Porto Velho-RO, Brazil
}

\begin{abstract}
Malaria is responsible for thousands of deaths each year. Currently, artemisinin combination therapy (ACT) is used as first-choice medication against the disease. However, the emergence of resistant strains prompts the search for alternative compounds. The present study aimed to investigate the antiplasmodial activities of natural triterpenes (compounds $\mathbf{1}$ and $\mathbf{2}$ ), and semisynthetic derivatives 1a, 1b, 1c, and 1d. Antiplasmodial assays were carried out using the SYBR Green technique, whereas cytotoxicity was evaluated by the MTT (3-(4,5-dimethylthiazol2-yl)-2,5-diphenyltetrazolium bromide) method. Hemolytic assays were performed on human erythrocytes. An in silico analysis of the compounds against PfENR (Plasmodium falciparum 2-trans-enoyl-reductase) was carried out by molecular docking. Experiments with 1, and its derivatives against $P$. falciparum showed that $\mathbf{1 a}$ was very similar in terms of biological activity to compound $\mathbf{1}$ (half maximal inhibitory concentration $\left(\mathrm{IC}_{50}\right)$ ca. $4 \mu \mathrm{M}$ ), whereas $\mathbf{1 b}, \mathbf{1 c}$, and $\mathbf{1 d}$ had reduced antiplasmodial activities $\left(\mathrm{IC}_{50}\right.$ between 8-103 $\left.\mu \mathrm{M}\right)$. The selectivity indexes of $\mathbf{1}$ and $\mathbf{1 d}$ for HepG2, and Vero cells were $>10$. Docking results partially agreed with the in vitro experiments, with 1 and $1 \mathrm{c}$ having the best and worst affinities with PfENR, respectively. In conclusion, the results showed that $\mathbf{1}$ and $\mathbf{1 d}$ may serve as biotechnological tools in the development of antimalarial drugs.
\end{abstract}

Keywords: Combretum, triterpenes, antiplasmodial, Plasmodium, enoyl-reductase

\section{Introduction}

Malaria is a disease transmitted by female mosquitos of the genus Anopheles, in which the etiological agents are some protozoan species of the genus Plasmodium. To date, five species are known to infect humans: P. falciparum, $P$. vivax, P. malariae, $P$. ovale, and P. knowlesi. ${ }^{1}$ This disease is responsible for an enormous social burden,

*e-mail: guilhermepassarini@ hotmail.com

Editor handled this article: José Walkimar M. Carneiro especially in sub-Saharan Africa. ${ }^{2}$ According to the World Health Organization (WHO), the estimated number of cases of the disease for 2018 was 228 million. ${ }^{3}$ The incubation period of the parasite varies from species to species, with the average being approximately two weeks. The symptoms are nonspecific, such as fever, myalgia, malaise, headache, and vomiting. Malaria may also present in a severe form, mainly caused by P. falciparum, which affects mostly immunocompromised patients, and can cause extensive damage to organs such as the brain, kidneys, and lungs. ${ }^{4}$ 
Regarding therapeutics, there are currently no vaccines available for the disease, with pharmacological treatment being the only intervention to treat the disease. The artemisinin combination therapy (TCA) is the standard treatment in most cases of P. falciparum malaria, ${ }^{5}$ replacing chloroquine due to the increasing appearance of resistant strains. However, with the increasing occurrence of resistance to artemisinin-based therapy, there is a need to search for new classes of drugs that can treat infections caused by future resistant strains. ${ }^{6}$ Natural products, mainly those derived from medicinal plants, played an important role in malaria chemotherapy, in which two medicinal plants, Cinchona officinalis, and Artemisia annua, resulted in two generations of antimalarial drugs: quinine and its derivatives, and artemisinin and its derivatives. ${ }^{7}$ Moreover, numerous medicinal plants are used in Africa by traditional populations to treat the disease, evidencing their potential for the discovery and development of antiplasmodial compounds. ${ }^{8}$

The above context motivates the search for compounds that can act on the parasite, reducing the impact of their resistance on malaria control and eradication programs. In this sense, natural products have been widely studied as pharmacological agents for the treatment of various diseases. Newman and $\mathrm{Cragg}^{9}$ show, for example, that a great proportion of the Food and Drug Administration (FDA)-approved drugs from 1981 to 2014 resulted directly or indirectly from natural products, especially medicinal plants.

Combretum leprosum, a species popularly known as "mofumbo", has a restricted distribution to South America, and is found in Brazil, Bolivia, and Paraguay. Its distinctive feature is the presence of whitish or yellowish, lepidote indumentum. ${ }^{10}$ Concerning this species, several studies have demonstrated its potential against a variety of diseases, including leishmaniasis, ${ }^{11-13}$ cell proliferation, ${ }^{14}$ cancer,${ }^{15}$ and bacterial infections. ${ }^{16}$ Based on this context, the present study aimed to investigate the antiplasmodial and cytotoxic activities of natural triterpenes (1 and $\mathbf{2}$ ) and semisynthetic derivatives of $\mathbf{1}$, as well as theoretically determine their binding affinities with the $P$. falciparum enzyme 2-trans-enoylACP-reductase ( $P f$ ENR) by molecular docking simulations.

\section{Experimental}

\section{Obtainment of natural and semisynthetic triterpenes}

Two natural triterpenes, $3 \beta, 6 \beta, 16 \beta$-trihydroxy-lup20(29)-ene (compound 1), and arjunolic acid (compound 2) were previously isolated by silica gel chromatography assisted by thin-layer chromatography, from the flowers, and leaves of $C$. leprosum. The natural compounds, along with the four semisynthetic derivatives: the diacetylated triterpene (compound 1a), diacetylated oxidated triterpene (compound 1b), triacetylated triterpene (compound 1c) and trioxidized triterpene (compound 1d) were obtained from the studies of Facundo et al..$^{17,18}$ The compounds are presented in Figure 1.

\section{In vitro assays against $P$. falciparum}

In the antimalarial activity assays, blood forms of a chloroquine-resistant $P$. falciparum (W2) clone were used. The parasites were cultured in human red blood cells under conditions established by Trager and Jensen ${ }^{19}$ with minor modifications. Cultivation was performed in culture flasks (TPP) with 2\% hematocrit diluted in Roswell Park Memorial Institute (RPMI) 1640 culture medium (SigmaAldrich, St. Louis, USA) supplemented with $25 \mathrm{mM}$ Hepes (Sigma-Aldrich, West Chester, PA, USA), $21 \mathrm{mM}$ sodium bicarbonate (Sigma-Aldrich, Waltham, USA), $11 \mathrm{mM}$
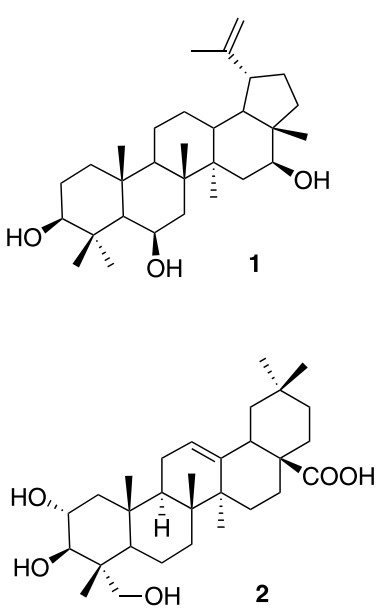
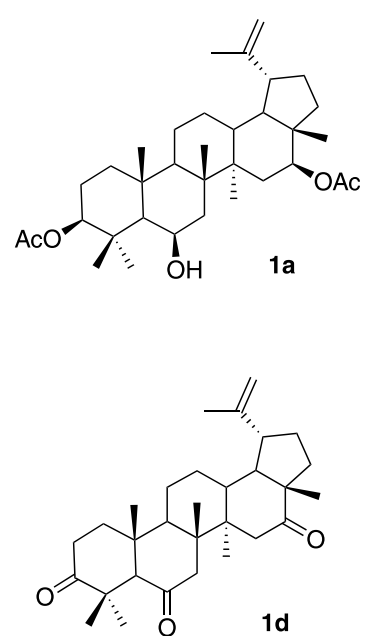

1d
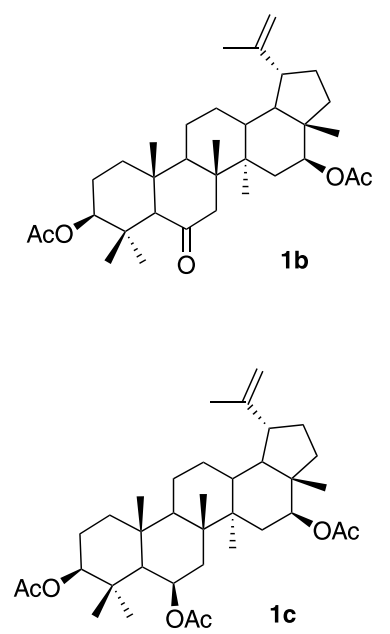

Figure 1. Compounds 1, 2 and semisynthetic derivatives 1a-1d 
glucose (Sigma-Aldrich, USA), $40 \mu \mathrm{g} \mathrm{mL}^{-1}$ gentamycin, and $10 \%(\mathrm{v} / \mathrm{v})$ albumax. ${ }^{19}$ Cultures were maintained in desiccators at $37{ }^{\circ} \mathrm{C}$ or in a gaseous mixture containing $5 \%$ $\mathrm{O}_{2}, 5 \% \mathrm{CO}_{2}$, and $90 \% \mathrm{~N}_{2}$.

\section{Synchronization of $P$. falciparum culture}

The predominant young trophozoite cultures that were used in the antiplasmodial assays were obtained through synchronization with sorbitol as described by Lambros and Vanderberg. ${ }^{20}$ Hematocrit and parasitemia were adjusted to 5 and $0.5 \%$, respectively.

\section{In vitro antiplasmodial assays}

Parasite cultures were distributed in 96-well microplates by adding $180 \mu \mathrm{L}$ per well of RPMI culture medium containing: $0.5 \%$ parasitemia and $2 \%$ hematocrit for the SYBR Green test. Before the addition of the parasite suspension, $20 \mu \mathrm{L}$ of $C$. leprosum compounds to be tested were added to the test plate in triplicate and at different concentrations $(100-1.56 \mu \mathrm{M})$. The positive control consisted of artemisinin $(17.7 \mathrm{nM})$ whereas the negative control consisted of infected red blood cells without the addition of drugs. The blank consisted of uninfected red blood cells with no treatment. Plates were incubated at $37{ }^{\circ} \mathrm{C}$ for $48 \mathrm{~h}$. After the incubation period, the fluorescence test was performed according to Lambros and Vanderberg. ${ }^{20}$ After, the SYBR Green fluorimetric assay was conducted to evaluate antiplasmodial activity. ${ }^{21}$ Plates containing the tested compounds and parasites had the supernatant discarded and for rinsing of the red cells, $100 \mu \mathrm{L}$ of $1 \times$ phosphate buffer solution (PBS) was added per well and then centrifuged at $700 \mathrm{~g}$ for $10 \mathrm{~min}$. Subsequently, the supernatant was discarded again and $100 \mu \mathrm{L}$ of the lysis buffer ( $20 \mathrm{mM}$ Tris, $\mathrm{pH}$ 7.5, $5 \mathrm{mM}$ ethylenediamine tetraacetic acid (EDTA), $0.008 \%, \mathrm{~m} / \mathrm{v}$ saponin, $0.08 \%$, v/v Triton X-100) was added with SYBR Green I ( $2 \mu \mathrm{L}$ of SYBR to each $10 \mathrm{~mL}$ of buffer) homogenized and transferred to the 96-well plate with $100 \mu \mathrm{L}$ of $1 \times$ PBS in which the reading was performed. After incubation for $30 \mathrm{~min}$ at room temperature, the fluorescence was measured in a fluorometer with excitation of $485 \mathrm{~nm}$ and an emission of $590 \mathrm{~nm}$ in a gain of 100 .

\section{Determination of the $\mathrm{IC}_{50}$}

The $\mathrm{IC}_{50}$ corresponds to the concentration at which the compound causes 50\% inhibition of parasite growth. We established that compounds with $\mathrm{IC}_{50}$ values less than or equal to $25 \mu \mathrm{M}$ were considered active, and below this threshold, inactive. ${ }^{22} \mathrm{The} \mathrm{IC}_{50}$ was determined by the software
Origin (OriginLab Corporation, Northampton, MA, USA), ${ }^{23}$ through non-linear regression of the concentrations tested.

In vitro cytotoxicity assays

\section{Culture of the HepG2 and Vero cells}

The adherent cell lines HepG2 and Vero were cultured as recommended..$^{24}$ They were maintained in $75 \mathrm{~cm}^{2}$ culture flasks supplemented in RPMI containing 5\% fetal bovine serum (FBS). Cells were maintained in $5 \% \mathrm{CO}_{2}$ in an incubator at $95 \%$ humidity at $37{ }^{\circ} \mathrm{C}$ and the medium of the flasks was replaced every two days.

\section{Preparation of the test plates}

For cytotoxicity assays, cells were washed with medium without FBS, treated with $1 \mathrm{~mL}$ of $0.25 \%$ trypsin-EDTA (Gibco/Invitrogen) and incubated at $37^{\circ} \mathrm{C}$ for 5 to $10 \mathrm{~min}$. $9 \mathrm{~mL}$ of complete medium was added to the resulting content of the trypsinization, followed by centrifugation at $1500 \mathrm{rpm}$ for $5 \mathrm{~min}$ at room temperature. The supernatant was discarded and the pellet was resuspended in complete medium containing $10 \%$ FBS. After counting in a Neubauer's chamber, the suspension was adjusted to $2 \times 10^{4}$ per $\mathrm{mL}$ and $180 \mu \mathrm{L}$ added to each well of the microplate. The cells were incubated for 12 to $16 \mathrm{~h}$ in a $\mathrm{CO}_{2}$ incubator at $37{ }^{\circ} \mathrm{C}$ for the adhesion process. Then, $20 \mu \mathrm{L}$ of complete medium containing different concentrations (500-3.16 $\mu \mathrm{M})$ of the compounds were added to the wells of the microplate. The plates were incubated for $72 \mathrm{~h}$ at $37^{\circ} \mathrm{C}$, $5 \% \mathrm{CO}_{2}$, and $95 \%$ humidity. The negative control consisted of untreated cells, and the positive control consisted of lysis buffer. The dimethyl sulfoxide (DMSO) concentration did not exceed $1 \%$. Due to the insufficient amount of samples, only the two natural triterpenes ( $\mathbf{1}$ and $\mathbf{2}$ ), and compound $\mathbf{1 d}$ were tested for their cytotoxic activity.

\section{Preparation of the test plates}

\section{MTT colorimetric assay}

Cytotoxicity was determined by the MTT method (3-((4,5-dimethylthiazol-2-yl)-2,5-diphenyl tetrazolium).$^{25}$ After the incubation period, $20 \mu \mathrm{L}$ of MTT at $5 \mathrm{mg} \mathrm{mL}^{-1}$ in PBS in each well, and the plates were incubated for $4 \mathrm{~h}$ at $37{ }^{\circ} \mathrm{C}$. At the end of that period, the culture medium, along with excess MTT, was discarded and then $100 \mu \mathrm{L}$ DMSO (Sigma-Aldrich, St. Louis, USA) was added to each well. Optical reading was performed using a microplate spectrophotometer at $570 \mathrm{~nm}$.

\section{Determination of $\mathrm{CC}_{50}$}

The cytotoxic concentration to $50 \%$ of the cells $\left(\mathrm{CC}_{50}\right)$ 
was determined from non-linear regression of the tested concentrations using the software Origin, as established for antiparasitic tests. ${ }^{23}$

\section{Selectivity index}

The selectivity index (SI) was calculated as the quotient between the $\mathrm{CC}_{50}$ and the $\mathrm{IC}_{50}$ of the respective compound. We considered that compounds whose selectivity index was greater than 10 were selective/non-toxic, whereas compounds with SI less than 10 were considered non-selective/toxic. ${ }^{26}$

\section{Hemolysis assay}

The hemolytic test was performed as previously established. ${ }^{27}$ The natural compound $\mathbf{1}$ and the semisynthetic derivatives 1a, and 1d were screened for their hemolytic activity for being active against $P$. falciparum. The concentrations tested were the same as those of the antiplasmodial assay. After dilution of the samples, $20 \mu \mathrm{L}$ of them were added to $180 \mu \mathrm{L}$ of an erythrocyte suspension to a $1 \%$ hematocrit in round-bottom 96 -well microplates. A solution of saponins $(0.05 \%)$ constituted the positive control (Sigma-Aldrich, St. Louis, USA) After preparation, the microplate was incubated for $30 \mathrm{~min}$ at a temperature of $37{ }^{\circ} \mathrm{C}$ with gentle shaking every $5 \mathrm{~min}$. Subsequently, the plate was centrifuged for $10 \mathrm{~min}$ at $1,500 \mathrm{rpm}$ and the supernatant was transferred to another flat-bottom 96-well microplate. Absorbance reading was performed at $540 \mathrm{~nm}$ on a microplate spectrophotometer.

\section{Molecular docking}

The triterpenes tested in vitro against the $\mathrm{W} 2$ of $P$. falciparum were evaluated in silico for their binding affinity with the $P$. falciparum enzyme 2-trans-enoylACP-reductase (PfENR). Since this enzyme is involved in the parasite's fatty acid biosynthesis FAS-II, which is not present in humans, it constitutes a promising target for screening antimalarial compounds. ${ }^{28}$ Since there is previous evidence $^{29}$ that triterpenes might act as PfENR inhibitors, we also decided to evaluate the compound of the abovementioned study, which presented in silico, and in vitro inhibition against the PfENR, the pentacyclic triterpene celastrol, in order to compare its results with those of the triterpenes evaluated in the present study. ${ }^{29}$

After the obtainment of the structures of all triterpenic analogs, the compounds were evaluated for their in silico affinity for 2-trans-enoyl-ACP-reductase through molecular docking simulations, in which the lowest $\Delta \mathrm{G}$ (Gibbs free energy) values, resulting from various positions of the screened compounds, were evaluated. The software used for the evaluation of the in silico interaction was AutoDock
4.0. ${ }^{30}$ The tridimensional structure of $P f E N R$ was retrieved from the PDB (Protein Data Bank), PDB code 3LT0.

The simulation grid was positioned at the active site with a size of $170 \times 170 \times 170$ points and centered at $45.515,84.230$ and $39.810 \AA$ for the coordinates $\mathrm{x}, \mathrm{y}$, and $\mathrm{z}$. The Lamarckian genetic algorithm was followed with protocol consisted of 10 independent runs per ligand, using an initial population of 150 randomly placed individuals, with $2.5 \times 10^{6}$ energy evaluations, a maximum number of 27000 iterations, a mutation rate of 0.02 , a crossover rate of 0.80 , and an elitism value of 1 . The analyses and visualizations were generated by the software USCF chimera. ${ }^{31}$

\section{Results}

The antiplasmodial assays showed that the natural compound $\mathbf{1}$ was the most active for P. falciparum with an $\mathrm{IC}_{50}=4.4 \mu \mathrm{M}$. The derivatives $\mathbf{1 a}$ and $\mathbf{1 d}$ were also considered active, with $\mathrm{IC}_{50}$ values of 4.56 and $8.9 \mu \mathrm{M}$, respectively. Compound $\mathbf{2}, \mathbf{1 b}$ and $\mathbf{1 c}$ were considered inactive $\left(\mathrm{IC}_{50}>25 \mu \mathrm{M}\right)$.

Concerning the comparison of the natural triterpene and its derivatives, it was observed that compound $\mathbf{1}$ obtained almost the same degree of activity as its diacetylated derivative (1a) at positions 3 and 16 of the molecule (both with $\mathrm{IC}_{50}<5 \mu \mathrm{M}$ ). Compound 1d was also considered active, although it has its potency decreased (Table 1). These three compounds were assessed for their hemolytic activity in human red blood cells, in which no hemolytic activity was found (data not showed). Compounds $\mathbf{1 b}$ and $\mathbf{1 c}$ were considered inactive $\left(\mathrm{IC}_{50} \geq 25 \mu \mathrm{M}\right)$. For the natural triterpene 1 and its derivative 1a, it was possible to determine the $\mathrm{IC}_{50}$ at a range from 13.07-0.19 $\mu \mathrm{M}$. However, for the other triterpenes (1b, 1c, and $\mathbf{1 d})$, the dose-response for the determination of the $\mathrm{IC}_{50}$ was established with concentrations ranging from $104.62-1.56 \mu \mathrm{M}$.

Since the natural triterpene 1, 1a, and 1d met the activity criteria of $<25 \mu \mathrm{M}$, they were investigated for their hemolytic potential to assess whether the antiplasmodial effects were due to hemolytic effects or direct action against the parasite. The results demonstrated (data not shown) that none of these compounds presented hemolysis for human red blood cells (RBC's) (13.07 to $0.19 \mu \mathrm{M}$ for compound $\mathbf{1}$ and 204.62-3.19 $\mu \mathrm{M}$ for compound 2 ).

\section{Cytotoxic assays}

Cytotoxicity assays were performed concurrently with the antiplasmodial assays, with some of the compounds being tested against $P$. falciparum. Cytotoxicity tests for 
Table 1. Antiplasmodial activity $\left(\mathrm{IC}_{50}\right)$, cytotoxicity $\left(\mathrm{CC}_{50}\right)$ and selectivity index $(\mathrm{SI})$ of the two natural triterpenes and synthetic derivatives against P. falciparum

\begin{tabular}{lccccc}
\hline Compound & $\mathrm{IC}_{50} / \mu \mathrm{M}$ & Vero $\left(\mathrm{CC}_{50}\right) / \mu \mathrm{M}$ & $\mathrm{HepG} 2\left(\mathrm{CC}_{50}\right) / \mu \mathrm{M}$ & ${\text { Selectivity index }(\mathrm{SI})^{\mathrm{a}}}^{\text {Selectivity index }(\mathrm{SI})^{\mathrm{b}}}$ \\
\hline $\mathbf{1}^{\mathrm{c}}$ & $4.4 \pm 2.33$ & $47.22 \pm 20.66$ & $50.35 \pm 0.32$ & 10.73 & 11.44 \\
$\mathbf{1 a}^{\mathrm{c}}$ & $4.56 \pm 0.41$ & - & - & - & - \\
$\mathbf{1 b}$ & $76.25 \pm 3.08$ & - & - & - & - \\
$\mathbf{1 c}$ & $103.38 \pm 0.26$ & - & - & - & - \\
$\mathbf{1}$ & $8.9 \pm 2.7$ & $\geq 500$ & $\geq 500$ & 256.18 & $\geq 56.18$ \\
$\mathbf{2}$ & $52.7 \pm 1.92$ & $151.31 \pm 10.51$ & $141.53 \pm 2.31$ & 2.87 & 2.68 \\
\hline
\end{tabular}

a Calculated in relation to Vero; ${ }^{\mathrm{b}}$ calculated in relation to HepG2; 'compounds that were not found to be hemolytic to human RBC's. All compounds were tested in triplicates. Artemisinin was used as the positive control. Mean obtained from two independent experiments, each one with samples in triplicate. For cytotoxicity assays, all compounds were tested in triplicates. Lysis buffer was used as the positive control.

Table 2. Binding affinities of the triterpenes and triclosan against the P. falciparum PfENR

\begin{tabular}{lccccc}
\hline Ligand & $\begin{array}{c}\text { Binding energy / } \\
\left(\text { (cal mol }^{-1}\right)\end{array}$ & $\mathrm{Ki} / \mu \mathrm{M}$ & No. of H-bonds & Protein residues (H-bonds) & Ligand atoms (H-bonds) \\
\hline Triclosan & -8.66 & 0.45136 & 4 & Tyr277, NAD & O \\
Celastrol & -6.58 & 9.54 & 0 & - & - \\
1 & -6.8 & 10.38 & 1 & NAD & O \\
1d & -6.63 & 13.70 & 1 & NAD, Asn218 & O \\
2 & -6.49 & 17.50 & 2 & Ala219 & O \\
1b & -3.55 & 2480 & 1 & - & - \\
1a & -2.7 & 10440 & 0 & Arg318 & O, H \\
1c & 3.8 & - & 1 & & \\
\hline
\end{tabular}

Ki: inhibition constant; H-bonds: hydrogen bonds; Tyr: tyrosine; Asn: asparagine; Ala: alanine; NAD: nicotinamide adenine dinucleotide.

the HepG2 and Vero cell lines were performed in parallel to antiparasitic tests, with the same compounds tested against Plasmodium falciparum.

The cytotoxicity results showed that compounds $\mathbf{1}, \mathbf{2}$, and $\mathbf{1 d}$ were inactive against the evaluated cell lines when considering the toxicity threshold of $25 \mu \mathrm{M}$ (Table 1). 1a, $\mathbf{1 b}$, and $\mathbf{1 c}$ were not tested due to an insufficient amount of samples. Compounds $\mathbf{1}$ and $\mathbf{1 d}$ presented selectivity indexes $>10$ for both cell lines.

\section{Molecular docking simulations}

The molecular docking simulations were used to predict the binding affinity of the triterpenes evaluated in vitro, against the enzyme PfENR (Figure 2). The results demonstrated that the natural triterpene $\mathbf{1}$ obtained the highest binding affinity amongst the triterpenes of the present study, with a $\Delta \mathrm{G}$ of $-6.8 \mathrm{kcal} \mathrm{mol}^{-1}$. Celastrol obtained an estimated $\Delta \mathrm{G}$ slightly higher than that of compound 1, being $=-6.58 \mathrm{kcal} \mathrm{mol}^{-1}$. The rest of the compounds obtained lower estimated binding affinities, with 1c obtaining a positive $\Delta \mathrm{G}$ value. The reference inhibitor triclosan obtained the best binding affinity, with an estimated $\Delta \mathrm{G}$ of $-8.66 \mathrm{kcal} \mathrm{mol}^{-1}$ (Table 2).

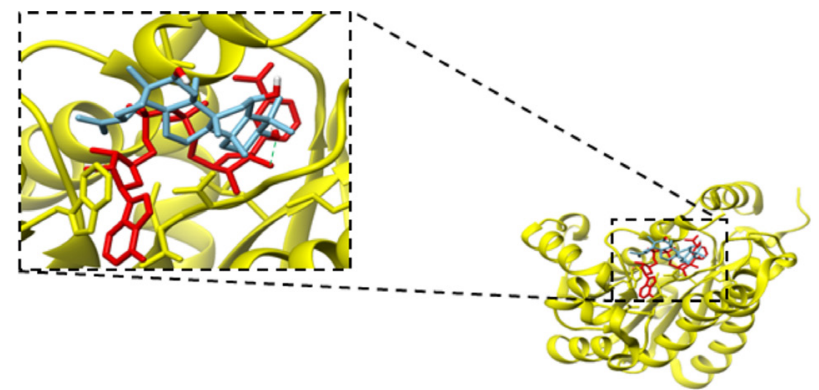

Figure 2. Molecular docking between PfENR (marked in yellow) and compound $\mathbf{1}$ (marked in light blue). The hydrogen bond is marked as a green traced line.

\section{Discussion}

The literature shows that there are several antiplasmodial studies $^{32-35}$ in which natural or semi-synthetic triterpenes are active against $P$. falciparum in vitro, evidencing the importance of prospecting and conducting antiplasmodial tests with this class of substances. The biological activity of the semisynthetic derivatives of the natural triterpene against $P$. falciparum showed that the substitution of all hydroxyls by acetyl groups results in loss of activity for the molecule. Compound 1a, which had acetyl groups replacing the hydroxyls at positions 3 and 16 but not at position 6 , 
maintained an $\mathrm{IC}_{50}$ very similar to that of the natural compound $\mathbf{1}\left(\mathrm{IC}_{50}\right.$ for $\mathbf{1}=4.4 \mu \mathrm{M} ; \mathrm{IC}_{50}$ for $\left.\mathbf{1 a}=4.56 \mu \mathrm{M}\right)$. On the other hand, compound $\mathbf{1 c}$, which had two of its hydroxyls replaced by acetyl groups and one oxidized, had its activity notably decreased than those of the parental compound $\mathbf{1}$ and the diacetylated compound 1a, with an $\mathrm{IC}_{50}$ of $76.25 \mu \mathrm{M}$. Concerning compound 1d, which had its hydroxyls oxidized in all 3 positions, its potency slightly decreased, with an $\mathrm{IC}_{50}$ of $8.9 \mu \mathrm{M}$. These results suggest that, for the natural triterpene (compound $\mathbf{1}$ in the present study), the hydroxyl at position $\mathrm{C}-6$ is crucial for biological activity. The presence of this hydroxyl may be crucial for interaction with the active site of the enzyme, for example, via the formation the hydrogen bonds. However, further studies are yet to be conducted to properly elucidate the mechanistic nature of this structure-activity relationship.

Natural compound 2 (arjunolic acid) was not considered active against $P$. falciparum, with an $\mathrm{IC}_{50}=52.7 \mu \mathrm{M}$. A previous study by da Silva et al. ${ }^{36}$ agrees with our observations, with an $\mathrm{IC}_{50}=61.18 \mu \mathrm{M}$ for arjunolic acid being reported for $P$. falciparum.

The importance of hydroxyls and other polar functional groups in the activity of lupane triterpenes for P. falciparum is also observed in other studies. It was found that two lupane triterpenes (messagenic acid $\mathrm{A}$ and messagenic acid B), both bearing carboxylates and $p$-coumarate groups in their radicals, obtained smaller $\mathrm{IC}_{50}$ 's (massagenic $\operatorname{acid~} \mathrm{A}, \mathrm{IC}_{50}=2.42 \mu \mathrm{M}$, massagenic acid $\mathrm{B}, \mathrm{IC}_{50}=6.14 \mu \mathrm{M}$ ) than lupeol, a lupane having only one hydroxyl, which was not active at $20 \mu \mathrm{g} \mathrm{mL}-1 \mathrm{IC}_{50}$ not shown). ${ }^{37}$ Betulone and lupenone, two other lupane triterpenes, were tested against a chloroquine-resistant strain (K1) of $P$. falciparum in a hypoxanthine incorporation assay, yielding $\mathrm{IC}_{50}$ of 3 and $4.7 \mu \mathrm{M}$, respectively. The difference between the two molecules was the presence of an alcohol (polar group) in a betulone radical, and the presence of a methyl (non-polar group) instead of the same lupenone radical. ${ }^{38}$

Some of the compounds here evaluated $(\mathbf{1}, \mathbf{1 a}$, and 1d) were previously investigated for their antileishmanial activity against Leishmania amazonensis promastigotes. ${ }^{12}$ In this previous study, the authors observed that the natural compound 1 was the most active against $L$. amazonensis, agreeing with the present study. However, they found that the replacement of two acetyl groups at positions 3 and 16 rendered the compound inactive. Finally, they observed that when the compound was trioxidized (compound 1d), it had an $\mathrm{IC}_{50}$ value similar to compound $\mathbf{1}$, contrasting with the present study.

Due to the hemolytic reports of triterpenes in the literature, and because the triterpenes of the present study were tested against erythrocytic stages of $P$. falciparum, a hemolytic assay was performed for the three compounds that complied with the threshold established for biological activity against $P$. falciparum: $\mathbf{1}, \mathbf{1 a}$, and $\mathbf{1 d} .^{39,40}$ The results demonstrated that the compounds did not cause hemolysis toward human erythrocytes, in contrast to the positive control, consisting of the saponin solution. This fact is probably due to the presence of few polar groups in the structures of the triterpenes and/or absence of sugars coupled to these, a characteristic that would confer amphiphilicity to these molecules. These results also suggest that the compounds act directly against the blood trophozoites, rather than causing their death by destroying their host cells.

Parallel to the antiplasmodial assays, cytotoxicity assays were performed to assess the possible damage that these compounds might cause on human cells. In this work, tests were performed against the following cell lines: HepG2, because they are hepatocytes, cells that naturally metabolize drugs and cells where Plasmodium spp. replicates in a phase of its cycle in the vertebrate host; ${ }^{41}$ and Vero cells, because they are a non-tumoral lineage that preserves characteristics of their original cells, besides being renal, playing a key role in the excretion of metabolites and being responsible for the production of EPO (erythropoietin). ${ }^{42}$ Studies in literature usually report cytotoxic activities from triterpenes. ${ }^{43}$ Interestingly, in our study, none of the evaluated triterpenes were classified as being cytotoxic for the two evaluated cell lines $\left(\mathrm{CC}_{50}>25 \mu \mathrm{M}\right)$, although it does not mean they are completely devoid of toxicity since some of the $\mathrm{CC}_{50}$ 's obtained were as low as $50 \mu \mathrm{M}$.

In fact, a study that investigated the cytotoxic activity of $\mathbf{1}$ against a wide variety of cancer cell lines showed that this triterpene obtained a $\mathrm{CC}_{50}$ of $13.35 \mu \mathrm{M}$ for the HepG2 cell line by the XTT (2,3-bis-(2-methoxy4-nitro-5-sulfophenyl)- $\mathrm{H}$-tetrazolium-5-carboxanilide)) method. ${ }^{15}$ This study also found that the triterpene is capable of inducing apoptosis in cancer cells, increasing the population of sub-G1 cells. Its mechanism of action in cancer cells appears to be the generation of free radicals and the induction of mutations. A study by Lacouth-Silva et al. ${ }^{44}$ showed that it is also cytotoxic to PBMC (peripheral blood mononuclear cells), with an estimated $\mathrm{CC}_{50}$ of $9.4 \mu \mathrm{M}$ after $15 \mathrm{~h}$ of incubation with compound 1. Compound 2 was considered to be cytotoxic against neither the HepG2 nor the Vero cells, with $\mathrm{CC}_{50}$ values of 141.53 and $151.31 \mu \mathrm{M}$, respectively. Indeed, some studies show that arjunolic acid has cytoprotective effects both in vitro and in vivo..$^{45,46}$

Interestingly, compound $\mathbf{1 d}$ has its cytotoxicity substantially decreased against HepG2 and Vero cells, with $\mathrm{CC}_{50}$ values being $\geq 500 \mu \mathrm{M}$ for both cell lines. Combined 
with its $\mathrm{IC}_{50}$, the selectivity index of $\mathbf{1 d}$ was the highest of the evaluated compounds ( $\geq 56.18$ ). Such a result encourages further analyses to investigate its antiplasmodial activity in vivo.

Since there is evidence that pentacyclic triterpenes may inhibit the PfENR, we screened all six compounds in a molecular docking simulation against this enzyme. ${ }^{29}$ We also included the validated compounds celastrol and triclosan in order to compare their results with the evaluated compounds. Such a computational approach has demonstrated valuable usefulness and may direct compound selection in a drug discovery pipeline. ${ }^{47}$ Compounds $\mathbf{1}$ and 1c obtained the best and worst binding affinities of the six compounds screened respectively, which agree with the in vitro experiments, where these compounds obtained the lowest and highest $\mathrm{IC}_{50}$ values against $P$. falciparum in vitro.

Thermodynamically, a ligand and a macromolecule represent a reaction system, where $\Delta \mathrm{G}$ values are negative if the reaction occurs favorably and the system is stable, and positive if the reaction is unfavorable. The positive values found for $1 \mathrm{c}\left(3.8 \mathrm{kcal} \mathrm{mol}^{-1}\right)$ indicate that the complex protein-ligand does not form a stable interaction and the reaction does not occur spontaneously and that therefore, this compound does not interfere with the activity of $P f E N R$.

\section{Conclusions}

Despite the in silico interaction of most triterpenes with PfENR, further in vitro experiments with the compounds, $P f E N R$, and its substrate are needed to confirm whether or not they are acting via PfENR inhibition. In conclusion, the results of this study demonstrated that the natural triterpene 1, and its derivative 1d presented interesting antiplasmodial activity in vitro, and interacted in silico with PfENR, and thus may serve as biotechnological tools in the development of antimalarial drugs.

\section{Supplementary Information}

Supplementary data (graphs containing the parasite growth inhibition data of the natural compound and the four derivatives) are available free of charge at http://jbcs.sbq.org.br as PDF file.

\section{Acknowledgments}

We are grateful to EpiAmo for granting financial resources to this study and $\mathrm{CNPq}$ for the scholarship concession. The authors are also grateful to Malaria and Leishmaniasis Bioassays Platform - Fiocruz (Rondônia).

\section{Author Contributions}

Guilherme M. Passarini was responsible for conceptualization, investigation, project administration, writing original draft; Amália S. Ferreira for conceptualization, investigation, methodology; Leandro S. Moreira-Dill for investigation, methodology, writing review and editing; Fernando B. Zanchi for conceptualization, investigation, software, writing review and editing; Aurileya G. de Jesus for investigation, methodology; Valdir A. Facundo for conceptualization, investigation, methodology, project administration, supervision and Carolina B. G. Teles for conceptualization, project administration, resources, supervision, visualization, writing review and editing.

\section{References}

1. Cox, F. E.; Parasites Vectors 2010, 3, 5.

2. Rosenthal, P. J.; John, C. C.; Rabinovich, N. R.; Am. J. Trop. Med. Hyg. 2019, 100, 239.

3. World Health Organization (WHO); World Malaria Report 2016; WHO: Geneva, 2016, https://apps.who.int/iris/bitstream/ handle/10665/252038/9789241511711-eng.pdf, accessed in November 2021.

4. Bartoloni, A.; Zammarchi, L.; Mediterr. J. Hematol. Infect. Dis. 2012, 4, e2012026.

5. Visser, B. J.; Van Vugt, M.; Grobusch, M. P.; Expert Opin. Pharmacother. 2014, 15, 2219.

6. Imwong, M.; Hien, T. T.; Thuy-Nhien, N. T.; Dondorp, A. M.; White, N. J.; Lancet Infect. Dis. 2017, 17, 1022.

7. Renslo, A. R.; ACS Med. Chem. Lett. 2013, 4, 1126.

8. Karunamoorthi, K.; Sabesan, S.; Jegajeevanram, K.; Vijayalakshmi, J.; Vector-Borne Zoonotic Dis. 2013, 13, 521.

9. Newman, D. J.; Cragg, G. M.; J. Nat. Prod. 2016, 79, 629.

10. Soares-Neto, R. L.; Cordeiro, L. S.; Loiola, M. I. B.; Rodriguesia 2014, 65, 685 .

11. Barros, N. B.; Migliaccio, V.; Facundo, V. A.; Ciancaglini, P.; Stábeli, R. G.; Nicolete, R.; Silva-Jardim, I.; Exp. Parasitol. 2013, 135, 337.

12. Teles, C. B. G.; Moreira, L. S.; Silva, A. A. E.; Facundo, V. A.; Zuliani, J. P.; Stábeli, R. G.; Silva-Jardim, I.; J. Braz. Chem. Soc. 2011, 22, 936.

13. Teles, C. B. G.; Moreira-Dill, L. S.; Silva, A. A.; Facundo, V. A.; Azevedo-Júnior, W. F.; Silva, L. H. P.; Motta, M. C. M.; Stábeli, R. G.; Jardim, I. S.; BMC Complementary Altern. Med. 2015, 15, 165.

14. Horinouchi, C. D. D. S.; Mendes, D. A. G. B.; Soley, S. B.; Pietrovski, E. F.; Facundo, V. A.; Santos, A. R. S.; Cabrini, D. A.; Otuki, M. F.; J. Ethnopharmacol. 2013, 145, 311.

15. Viau, C. M.; Moura, D. J.; Facundo, V. A.; Saffi, J.; BMC Complementary Altern. Med. 2014, 14, 280. 
16. Evaristo, F. F. V.; Albuquerque, M. R. J. R.; Santos, H. S.; Bandeira, P. N.; Ávila, F. N.; Silva, B. R.; BioMed. Res. Int. 2014, ID 729358.

17. Facundo, V. A.; Rios, K. A.; Moreira, L. S.; Militão, J. S. L. T.; Stabeli, R. G.; Braz-Filho, R.; Silveira, R.; Rev. Latinoam. Quim. 2008, 36, 76.

18. Facundo, V. A.; Andrade, C. H. S.; Silveira, E. R.; Braz-Filho, R.; Hufford, C. D.; Phytochemistry 1993, 32, 411.

19. Trager, W.; Jensen, J. B.; Science 1976, 193, 673.

20. Lambros, C.; Vanderberg, J. P.; J. Parasitol. 1979, 65, 418.

21. Smilkstein, M.; Sriwilaijaroen, N.; Kelly, J. X.; Wilairat, P.; Riscoe, M.; Antimicrob. Agents Chemother. 2004, 48, 1803.

22. Cos, P.; Vlietinck, A. J.; Berghe, D. V.; Maes, L.; J. Ethnopharmacol. 2006, 106, 290.

23. Origin, 5.0; OriginLab Corporation, Northampton, MA, USA, 2005.

24. Calvo-Calle, J. M.; Moreno, A.; Eling, W. M. C.; Nardin, E. H.; Exp. Parasitol. 1994, 79, 362.

25. Mosmann, T.; J. Immunol. Methods 1983, 65, 55.

26. Weniger, B.; Robledo, S.; Arango, G. J.; Deharo, E.; Aragón, R.; Munoz, V.; Callapa, J.; Lobstein, A.; Anton, R.; J. Ethnopharmacol. 2001, 78, 193.

27. Wang, C.; Qin, X.; Huang, B.; He, F.; Zeng, C.; Biochem. Biophys. Res. Commun. 2010, 402, 773.

28. Qidwai, T.; Khan, F.; Chem. Biol. Drug Des. 2012, 80, 155.

29. Tallorin, L.; Durrant, J. D.; Nguyen, Q. G.; McCammon, J. A.; Bukart, M. D.; Bioorg. Med. Chem. 2014, 22, 6053.

30. Trott, O.; Olson, A. J.; J. Comput. Chem. 2010, 31, 455.

31. Pettersen, E. F.; Goddard, T. D.; Huang, C. C.; Couch, G. S.; Greenblatt, D. M.; Meng, E. C.; Ferrin, T. E.; J. Comput. Chem. 2004, 25, 1605.

32. Nogueira, C. R.; Lopes, L. M. X.; Molecules 2011, 16, 2146.

33. Isah, M. B.; Ibrahim, M. A.; Mohammed, A.; Aliyu, A. B.; Masola, B.; Coetzer, T. H. T.; Parasitology 2016, 143, 1219.

34. Ramalhete, C.; Lopes, D.; Molnár, J.; Mulhovo, S.; Rosário, V. E.; Ferreira, M. U.; Bioorg. Med. Chem. 2011, 19, 330.
35. Ramalhete, C.; Cruz, F. P.; Mulhovo, S.; Sousa, I. J.; Fernandes, M. X.; Prudêncio, M.; Ferreira, M. U.; Bioorg. Med. Chem. 2014, 15, 3887.

36. da Silva, T. B. C.; Alves, V. L.; Mendonça, L. V. H.; Conserva, L. M.; da Rocha, E. M. M.; Andrade, E. H. A.; Lemos, R. P. L.; Pharm. Biol. 2004, 42, 94.

37. Suksamrarn, A.; Tanachatchairatana, T.; Kanokmedhakul, S.; J. Ethnopharmacol. 2003, 88, 275.

38. Gachet, M. S.; Kunert, O.; Kaiser, M.; Brun, R.; Zehl, M.; Keller, W.; Munoz, R. A.; Bauer, R.; Schuehly, W.; J. Nat. Prod. 2011, $74,559$.

39. Vo, N. N. Q.; Fukushima, E. O.; Murakana, T.; J Nat. Med. 2016, 71, 50 .

40. Chwalek, M.; Lalun, N.; Bobichon, H.; Plé, K.; VoutquenneNazabadioko, L.; Biochim. Biophys. Acta (BBA) - Gen Subj. 2006, 1760, 1418.

41. Matos, C. T.; da Silva, M. L.; Cabrita-Santos, L.; Portal, M. D.; Inês, P.; Cell. Microbiol. 2016, 18, 437.

42. Jelkmann, W.; J. Physiol. 2011, 589, 1251.

43. Patocka, J.; J. Appl. Biomed. 2003, 1, 7.

44. Lacouth-Silva, F.; Xavier, C. V.; Setúbal, S. S.; Pontes, A. S.; Nery, N. M.; Castro, O. B.; Fernandes, C. F. C.; Honda, E. R.; Zanchi, F. B.; Calderon, L. A.; Stábeli, R. G.; Soares, A. M.; Silva-Jardim, I.; Facundo, V. A.; Zuliani, J. P.; BMC Complementary Altern. Med. 2015, 15, 420.

45. Ghosh, J.; Das, J.; Manna, P.; Sil, P. C.; Toxicol. In Vitro 2008, 22, 1918 .

46. Elsherbiny, N. M.; Eladl, M. A.; Al-Gayyar, M. M.; Cytokines 2016, 77, 26.

47. Baig, M. H.; Ahmad, K.; Roy, S.; Ashraf, J. M.; Adil, M.; Siddiqui, M. H.; Khan, S.; Kamal, M. A.; Provazník, I.; Choi, I.; Curr. Pharm. Des. 2016, 22, 572.

Submitted: September 3, 2021

Published online: December 10, 2021 